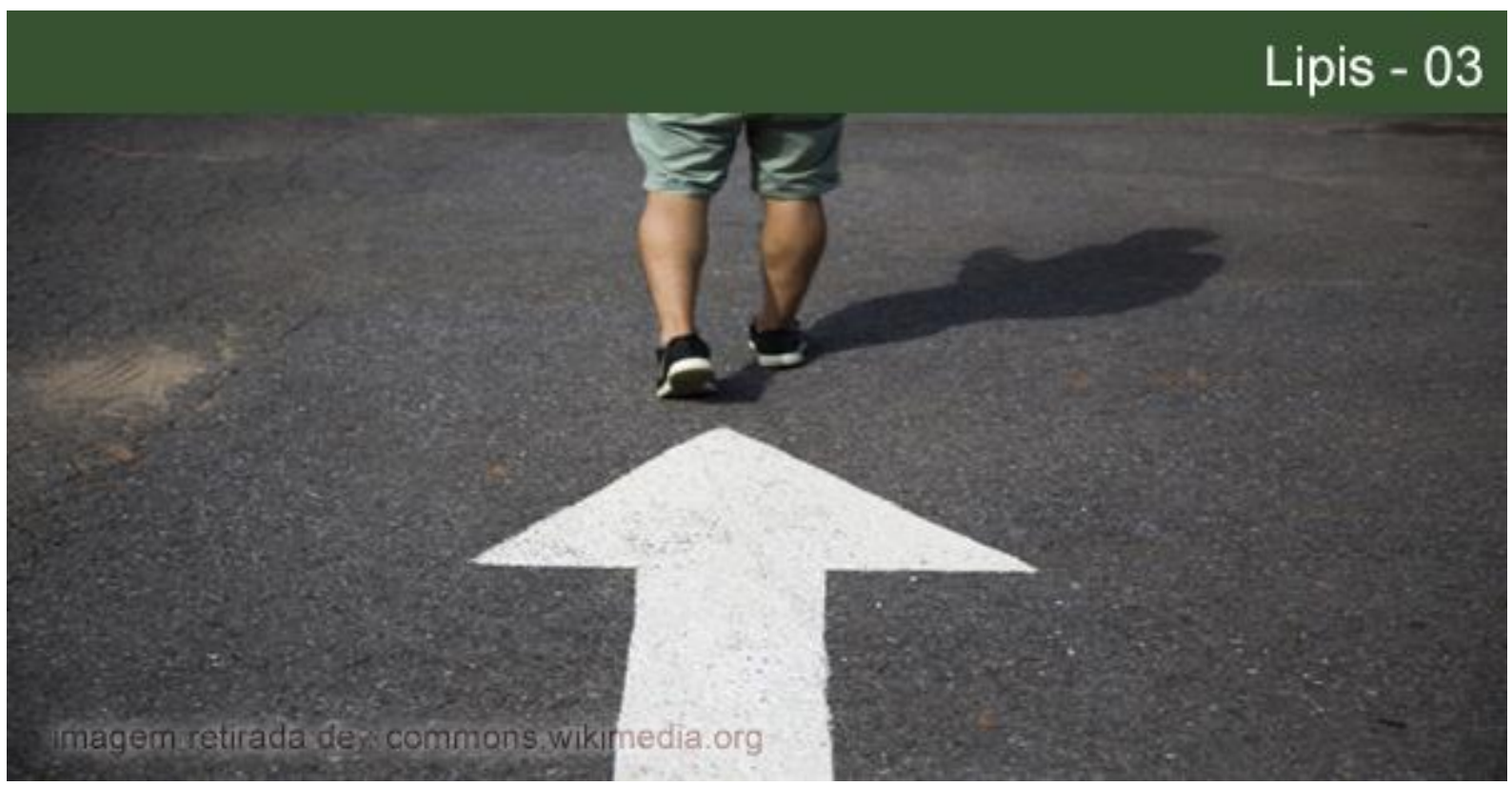

\title{
ADOLESCENTES EM PRIVAÇÃO DE LIBERDADE, TERRITÓRIOS E POLÍTICAS PÚBLICAS
}

\begin{abstract}
Maria Tereza Azevedo Silva
Psicóloga do Departamento Geral de Ações Socioeducativas - Degase. Doutoranda em Psicologia Clínica pela Pontifícia Universidade Católica (PUC-Rio). Pós-Graduada em Psicologia Jurídica pela Universidade do Estado do Rio de Janeiro (UERJ), em Violência Doméstica contra Crianças e Adolescentes pela Universidade de São Paulo (USP), em Terapia Familiar pela Universidade Federal do Rio de Janeiro (UFRJ) e em Análise Institucional pelo Instituto Brasileiro de Psicologia (IBRAPSI). E-mail: mariaterezaazevedosilva@gmail.com.
\end{abstract}

\section{Maria Helena Zamora}

Professora da Graduação e da Pós-Graduação em Psicologia da Pontifícia Universidade Católica (PUC-Rio). Doutora em Psicologia Clínica pela PUC-Rio. Vice-coordenadora do Laboratório Interdisciplinar de Pesquisa e Intervenção Social (LIPIS), da PUC-Rio.E-mail: zamoramh@gmail.com.

Resumo: Este artigo pretende discutir dados do recorte de uma pesquisa intitulada "Trajetórias de Vida de Jovens em Situação de Privação de Liberdade no Sistema Socioeducativo do Estado do Rio de Janeiro" (JULIÃO; MENDES, 2019), que teve como objetivo constituir, a partir da visão dos adolescentes e jovens em privação de liberdade no estado, um conhecimento aprofundado acerca de suas vidas e percepções, apontando para a promoção de transformações produtivas em seu processo socioeducativo. Foram destacados neste artigo subtemas da pesquisa para empreender uma breve reflexão, dialogando com textos relevantes, considerando as violências vividas por essa população e a perda de muitas vidas desses jovens. Os subtemas escolhidos foram: o enfrentamento da violência e a vulnerabilidade, relações com representantes da lei, aspectos de saúde e sexualidade, a família e sua realidade, o território enquanto espaço de vivência dos adolescentes e a interação deles com as políticas públicas a eles destinadas. $\mathrm{O}$ objetivo do presente trabalho, ao comentar, discutir e aprofundar a pesquisa "Trajetórias" é acentuar a importância de se conhecer as relações sociais que compõem as vidas desses adolescentes e as interações com os recursos e oportunidades de suas redes regionais. Assim, procura-se ponderar sobre a possibilidade de investimentos públicos, assinalando demandas, seja no campo institucional ou em seus espaços de vida, desconstruindo preconceitos diversos, para abertura de novas vias de desenvolvimento e existência cidadã.

Palavras-chave: Adolescentes em privação de liberdade. Violência. Famílias. Territórios. Políticas Públicas.

\section{POLÊM!CA $\mid$ LABORE}

Polêmica - Revista Eletrônica da Uerj - Rua São Francisco Xavier, 524, $1^{\circ}$ andar bloco D, sl.1001 • Tels.: +55 21 2334-4088 / 4087 • http://www.e-publicacoes.uerj.br/index.php/polemica/index http://www.labore.uerj.br • laboreuerj@yahoo.com.br 


\title{
ADOLESCENTS IN JUVENILE DETENTION, TERRITORIES AND PUBLIC POLICIES
}

\begin{abstract}
This article intends to discuss data from part of a research entitled "Life Trajectories of Young People in Juvenile Detention in the Socio-Educational System of the State of Rio de Janeiro" (JULIÃO; MENDES, 2019). Its aim is to construct a consistent in-depth knowledge on their lives and perceptions from the point of view of young people in detention, pointing to the promotion of productive changes in their socio-educational process. This article highlighted the subthemes of the research to take a brief reflection, dialoguing with relevant texts and considering the different types of violence experienced by this population and the many losses of lives of these young people. The chosen subthemes were: the confrontation of violence and vulnerability, relationships with law enforcement representatives, health and sexuality aspects, the family and its reality, the territory as a living space for adolescents and their interaction with public policies aimed at them. The purpose of this paper, by commenting, discussing and deepening the research "Trajectories" is to emphasize the importance of knowing the social relations that make up the lives of these adolescents and the interactions with the resources and opportunities of their regional networks. Thus, we seek to consider the possibility of public investments, pointing out demands to open new ways of development and citizen existence, either in the institutional field or in their living spaces, deconstructing different prejudices.
\end{abstract}

Keywords: Adolescents in juvenile detention. Violence. Families. Territories. Public Policies.

\section{Introdução}

O presente artigo tem como objetivo apresentar e refletir sobre um amplo estudo acerca de adolescentes em privação de liberdade no Rio de Janeiro. Trata-se da pesquisa "Trajetórias de Vida de Jovens em Situação de Privação de Liberdade no Sistema Socioeducativo do Estado do Rio de Janeiro" (JULIÃO; MENDES, 2019), denominada aqui apenas como "Trajetórias", que foi realizada, entre 2016 e 2018, por solicitação da própria gestão do Departamento Geral de Ações Socioeducativas do estado do Rio de Janeiro - Degase ${ }^{1}$ à Assessoria de Sistematização Institucional - ASIST, um setor do departamento, objetivando conhecer demandas e lacunas existentes na execução das medidas, através da visão dos adolescentes em cumprimento de medida socioeducativa de internação.

A investigação foi realizada também com a participação de pesquisadores da Universidade Federal Fluminense - UFF, formando uma equipe interdisciplinar, com a coordenação em coparceira das duas instituições. A metodologia utilizada foi quantitativa, com a aplicação de 447 questionários no total, com adolescentes de ambos os sexos, internados por cometimento de ato infracional, e teve lugar em todas as unidades de cumprimento de medida socioeducativa de internação que então existiam no Estado no período do levantamento dos

\footnotetext{
${ }^{1} \mathrm{O}$ Degase é um órgão do estado do Rio de Janeiro, que executa as medidas socioeducativas de internação e de restrição de liberdade junto aos adolescentes em conflito com a lei, e está lotado na Secretaria Estadual de Educação, o que representa um possível ganho no sentido de maiores investimentos na socioeducação pelo viés da formação de pessoas em desenvolvimento e não principalmente perpassados por uma gestão com maior foco na segurança pública.
}

\section{POLÊM!CA $\mid$ LABORË}

Polêmica - Revista Eletrônica da Uerj - Rua São Francisco Xavier, 524, $1^{\circ}$ andar bloco D, sl.1001 • Tels.: +55 21 2334-4088 / 4087 • http://www.e-publicacoes.uerj.br/index.php/polemica/index http://www.labore.uerj.br • laboreuerj@yahoo.com.br 
dados, no ano de 2016: cinco unidades de internação masculina e uma unidade feminina (JULIÃO; MENDES, 2019, p. 17-18).

A equipe considerou a importância de sensibilizar para a pesquisa os envolvidos no cotidiano institucional por reconhecer que sua realização mobiliza ações dentro das unidades e aspectos emocionais dos participantes. Realizou-se um preparo para a entrada da equipe em cada unidade, apresentando a proposta e discutindo a organização para sua aplicação, considerando o quantitativo de formulários por cada unidade. O total de questionários, calculado por estatística dentro de critérios de confiabilidade e margem de erro, totalizou um plano amostral final de 307 questionários. Elaborou-se um pré-teste com a participação de um grupo reduzido de adolescentes, em uma das unidades masculinas e na feminina.

Outro aspecto ressaltado pela equipe de pesquisa foi a importância do compromisso de devolutivas dos resultados para todas as unidades e o sistema como um todo, para as redes intersetoriais de referência para os adolescentes e suas famílias, assim como para a sociedade, com informação e debates.

O presente trabalho tem como objetivos a divulgação da pesquisa "Trajetórias" e promover um breve debate sobre alguns dos seus dados, como vulnerabilidades que esses adolescentes enfrentam, alguns aspectos sobre saúde e sexualidade, família e territórios - sendo este último tópico mais explorado. O território tem muita importância como espaço de vivência dos adolescentes quando em liberdade e é também o local e via de acesso a políticas públicas. Os subtemas elencados - apresentados na sequência - podem compor um panorama de experiências desses jovens, apontando para possíveis caminhos a serem construídos a partir desse conhecimento e do que vem sendo desenvolvido em estudos em torno dessa temática na atualidade.

\section{Violência e vulnerabilidade}

Sobre a vivência de violência, há um dado impactante: 49,8\% dos adolescentes declararam que já sofreram agressões violentas, a ponto de serem machucados fisicamente. Este percentual se refere a qualquer tipo de agressão que possam ter sofrido em suas vidas, por qualquer agente agressor.

Na relação com a lei e com autoridades diversas, 64,8\% dos participantes afirmaram já ter sofrido alguma violência, seja em instituições socioeducativas ou em outros lugares de

\section{POLÊM!CA $\mid$ LABORE}

Polêmica - Revista Eletrônica da Uerj - Rua São Francisco Xavier, 524, $1^{\circ}$ andar bloco D, sl.1001 • Tels.: +55 21 2334-4088/4087 • http://www.e-publicacoes.uerj.br/index.php/polemica/index http://www.labore.uerj.br • laboreuerj@yahoo.com.br 
atendimento do Estado. 86\% deles declararam já terem sofrido violência por parte de policiais (JULIÃO; MENDES, 2019, p. 41).

Pode-se afirmar que uma grande parte desta população lida com muitos enfrentamentos, com agressões e violências, em diversos aspectos da vida, já naturalizada. Isso também demanda atenção e cuidado para superação de possíveis traumas e percalços para o alcance de um bom desenvolvimento.

Zappe e Dias (2012), em estudo acerca de relações entre violência, relações familiares e envolvimento de adolescentes em atos infracionais, assinalam a presença da violência já ocupando um lugar de grave problema social, tendo rebatimentos na saúde dos indivíduos e desta população jovem. Apontam as autoras como juventude e violência constituem uma associação problemática, sendo algo a ser mais compreendido o encontro de jovens que cometeram violência também terem enfrentado violência (ZAPPE; DIAS, 2012, p. 389). Sublinham as autoras que a existência de violência familiar na vida dos adolescentes em conflito com a lei pode ser um indicativo de que vão ser atingidos por outras violências, "sobretudo uma violência estrutural, relacionada às condições socioeconômicas de vida. Os adolescentes pesquisados vivem em regiões precárias, fortemente marcadas pela presença de criminalidade e do tráfico de drogas" (ZAPPE; DIAS, 2012, p. 392). As famílias estão na composição desta violência estrutural, precisando ser consideradas a partir da ausência do amparo social, o que remete a uma lacuna de políticas públicas adequadas nos territórios desses jovens.

Vicentin (2011), em seu texto acerca do sofrimento de adolescentes que cometeram atos infracionais e estão em medida socioeducativa de internação, assinala a questão da violência que perpassa seus corpos e suas vidas. A autora sublinha que o movimento de impingir aos jovens um carimbo de "violentos" na verdade provoca uma ação de exclusão e desordem no meio social e coloca a importância de poder refletir sobre a violência em seus efeitos produtivos, também relativos à subjetividade gerada a partir da associação de violência e juventude (VICENTIN, 2011, p. 106).

Ela aponta, também, a configuração de um estilo corporal para lidar com a violência existente, uma forma de adaptação e proteção ao que se enfrenta no dia a dia, associada com a precarização nas relações, com espaços discriminados, socioeconomicamente prejudicados, onde há a pobreza e criminalização de seus habitantes. Aborda a autora que a força de ações dos adolescentes está não só revelando o controle a que ficam submetidos, a exclusão que

\section{POLÊM!CA $\mid$ LABORE}

Polêmica - Revista Eletrônica da Uerj - Rua São Francisco Xavier, 524, $1^{\circ}$ andar bloco D, sl.1001 • Tels.: +55 21 2334-4088 / 4087 • http://www.e-publicacoes.uerj.br/index.php/polemica/index http://www.labore.uerj.br • laboreuerj@yahoo.com.br 
enfrentam, mas buscando como desconstruir este engessamento de suas vidas, já perpassadas por tantas dificuldades (VICENTIN, 2011, p. 106-107).

Prosseguindo na análise de dados, em relação à possibilidade de rever a própria conduta, na pergunta: caso pudessem voltar no tempo, se cometeriam ou não o ato infracional, 15,3\% dos adolescentes manifestaram que cometeriam o mesmo ato. Por outro lado, 67\% afirmaram que não cometeriam o mesmo ato infracional ou qualquer outro se tivessem essa oportunidade, e $67,1 \%$ dos pesquisados, em outra questão, enunciaram ter arrependimento pelo ato infracional cometido (JULIÃO; MENDES, 2019, p. 48).

É evidente que não se procurou saber se tais informações são sinceras ou não. O fato de se proporem a responder ao questionário sem identificação, de saberem que não teriam qualquer recompensa com isso, de não negarem o cometimento de atos infracionais, de fazerem relatos espontâneos e às vezes não solicitados - todo esse conjunto de fatores - sugere respostas confiáveis.

Os adolescentes enfrentaram situações complexas, marcadas pela violência de vários tipos, além de viverem dificuldades de subsistência. Ao expressarem o desejo de rever suas atitudes, segundo suas respostas, é possível que a dura realidade já vivida lhes dê um certo conhecimento da própria vulnerabilidade e da importância de oportunidades para poderem encontrar outros caminhos.

\section{Saúde, sexualidade e visita íntima}

Os adolescentes, em grande maioria, já iniciaram sua vida sexual. 95,1\% declararam ter relações heterossexuais e 6,5\% afirmaram manter relações sexuais homoafetivas. A maioria $(69,7 \%)$ declarou estabelecer simultaneamente relações sexuais com parceiros diversos.

A atenção à saúde do adolescente é imprescindível, em seus diversos aspectos. Apesar de surpreender que $85 \%$ declararam ter cuidados com a saúde física, 23,1\% afirmaram não usar métodos preservativos a fim de evitar doenças sexualmente transmissíveis (DSTs) e gravidez e $29 \%$ declararam uso eventual de alguma proteção. Sobre o conhecimento acerca da temática DSTs, 52,1\% responderam que não têm dúvidas e 9,4\% às vezes têm dúvidas sobre o assunto (JULIÃO; MENDES, 2019, p. 53). Isto sinaliza a carência, tanto pelo Degase como pelos demais setores do Estado, de investimentos em campanhas públicas em torno da saúde sexual,

\section{POLÊM!CA $\mid$ LABORE}

Polêmica - Revista Eletrônica da Uerj - Rua São Francisco Xavier, 524, $1^{\circ}$ andar bloco D, sl.1001 • Tels.: +55 21 2334-4088 / 4087 • http://www.e-publicacoes.uerj.br/index.php/polemica/index http://www.labore.uerj.br • laboreuerj@yahoo.com.br 
com orientações não apenas acerca da prevenção de problemas e agravos, mas também de cuidados básicos sobre o corpo.

Acerca da prática de relações sexuais entre adolescentes nos alojamentos durante a internação, 67,4\% informaram não ter conhecimento do fato e 30\% declararam que acontece. A implantação da visita íntima deveria ser feita a fim de atender as diretrizes do artigo 68 da Lei 12594/2012, conhecida como Sistema Nacional de Atendimento Socioeducativo - SINASE (BRASIL, 2012a), que são basicamente as seguintes: a garantia do direito à visita íntima ao adolescente casado ou que viva, comprovadamente, em união estável; o que se completa no artigo 69, no qual define-se que o programa de atendimento fará a identificação do visitante e seu registro, passando a ter um documento pessoal, não transferível, para a entrada para a visita íntima.

O Degase, apesar de ter feito uma forte mobilização na construção interdisciplinar, interinstitucional e intersetorial de um programa denominado "Programa Visita Afetiva", de 2014, para implantação da visita íntima, que abrange a elaboração de um programa de saúde e sexualidade, além de informações às famílias e aos servidores (SILVA; ZAMORA, 2014; LESSA et al., 2015), ainda não efetivou este direito nas unidades de privação de liberdade (SILVA, 2018).

A possibilidade do exercício da sexualidade produz reverberações no próprio sistema e na sociedade. É preciso reafirmar o respeito aos direitos e superar discriminações já existentes e que alimentam violências na instituição, fora e além dela (SILVA, 2018, p. 158).

\section{Família, novos arranjos e novas leis}

O conceito de família na contemporaneidade, sempre com possibilidades de transformações contínuas em culturas e realidades diferenciadas, abrange os vínculos afetivos entre seus membros, superando um conceito anterior, delimitado apenas por laços biológicos, por consanguinidade.

Na Constituição Federal (BRASIL, 1988), no artigo 226, afirma-se a família como a base da sociedade e com direito à especial proteção do Estado; em seu parágrafo quarto compreende "como entidade familiar a comunidade formada por qualquer dos pais e seus descendentes". A nova definição legal, pautada na própria Constituição, fortalece um conceito

\section{POLÊM!CA $\mid$ LABORE}

Polêmica - Revista Eletrônica da Uerj - Rua São Francisco Xavier, 524, $1^{\circ}$ andar bloco D, sl.1001 • Tels.: +55 21 2334-4088 / 4087 • http://www.e-publicacoes.uerj.br/index.php/polemica/index http://www.labore.uerj.br • laboreuerj@yahoo.com.br 
amplo de família ao reconhecer as uniões estáveis (artigo 226, parágrafo terceiro) e os filhos tidos em toda e qualquer relação (artigo 227, parágrafo sexto).

O Estatuto da Criança e do Adolescente (BRASIL, 1990), promulgado em 1990, em seu artigo 25, afirma que a família extensa é aquela formada "para além da unidade pais e filhos ou da unidade do casal, formada por parentes próximos com os quais a criança ou adolescente convive e mantém vínculos de afetividade". Nesta mesma direção, um documento importante é o Plano Nacional de Promoção, Proteção e Defesa do Direito de Crianças e Adolescentes à Convivência Familiar e Comunitária (BRASIL, 2006). O Plano citado afirma que a família se configura pela formação de um grupo de pessoas unidas por laços consanguíneos, de aliança e afinidade (p. 24)

Referente também às novas legislações e mudanças na constituição de relações familiares, Vilhena et al. (2011) assinalam como a decisão do Supremo Tribunal Federal, em 2011, de reconhecimento da constitucionalidade das uniões homoafetivas provocou uma onda de opiniões referentes a família e a ameaça de seu desmonte, a fragmentação dos valores morais existentes, entre outras posições contrárias. Apontam as autoras que seria importante refletir sobre qual é o significado da família: deve essa ser vista como abrigo ou prisão, como local de encontros ou isolamento, como espaço para transformações ou alienação? Apontam, ainda, que são necessárias transformações para lidar com os afetos e suas expressões, diante de grandes mudanças na atualidade (VILHENA et al., 2011, p. 1643).

Atualmente, a família brasileira é, portanto, compreendida de diversas formas, dentro de múltiplas definições, seja pela legislação ou pela academia. Ela mudou sua composição, com um número menor de membros, podendo se organizar com somente um dos responsáveis a frente da família, caracterizando-a como monoparental. E é importante a compreensão de que cada definição de família está relacionada a um determinado momento histórico, sendo mais válido falar de famílias, de forma a abarcar a multiplicidade de relações existentes em suas formas singulares (VILHENA et al., 2011, p. 1655).

Os núcleos familiares, em sua variada composição e desenho demandam, assim, atenção e orientação para que o exercício parental possa bem exercer suas funções protetoras. É indicado que uma política de atenção às famílias seja afinal posta em prática, promovendo ações que construam apoios para as transformações necessárias em suas trajetórias (SILVA, 2018).

\section{POLÊM!CA $\mid$ LABORE}

Polêmica - Revista Eletrônica da Uerj - Rua São Francisco Xavier, 524, $1^{\circ}$ andar bloco D, sl.1001 • Tels.: +55 21 2334-4088 / 4087 • http://www.e-publicacoes.uerj.br/index.php/polemica/index http://www.labore.uerj.br • laboreuerj@yahoo.com.br 
Na pesquisa "Trajetórias", 80,8\% dos adolescentes acreditam que seus pais os percebem ou avaliam positivamente. Eles acreditam que seus próprios pais os achem bons, responsáveis $(63,5 \%)$, estudiosos $(42,3 \%)$, não agressivos $(70 \%)$, pessoas que colaboram em casa $(74,3 \%)$ e estão em sintonia com os problemas e enfrentamentos da família (80\%).

Segundo os adolescentes, no que se refere a como acham que seus pais exercem o acompanhamento parental - ou seja, deles, filhos, no cotidiano - metade deles afirma que suas famílias sabem o que estão fazendo e a outra metade desconhece (JULIÃO; MENDES, 2019). Para os jovens, 77\% dos pais tentam acompanhar os filhos, apesar de que para eles um percentual expressivo dos responsáveis desconhece com quem o adolescente está, a que horas volta e/ou se volta (mesmo determinando o horário), se o filho (ou familiar) conta como e onde gasta o dinheiro, entre algumas outras especificidades do cotidiano familiar (JULIÃO; MENDES, 2019, p. 51).

A família é um espaço de convivência de grande importância para os adolescentes, o que pode potencializar novos rumos para seus componentes, principalmente, quando é construtiva e protetora (SILVA, 2018). A atenção às famílias dos adolescentes em conflito com a lei é muito importante também para a construção e prática do Plano Individual de Atendimento (PIA), previsto no Estatuto e no SINASE. A compreensão da singularidade de cada família, sua forma de se organizar e se constituir, seu pertencimento social no território, reafirmam que o trabalho a ser feito deve levar em conta diferenciações específicas de realidade e núcleo familiar.

Camuri et al. (2012, p. 47-48) apontam, em pesquisa com familiares no sistema socioeducativo, as afirmativas de serem culpabilizados pela sociedade, assim como pelos agentes socioeducativos e do sistema jurídico, pelo comportamento infracional do filho e sua apreensão, sendo inclusive, por vezes ofendidos diretamente. É de suma importância o desmonte de uma pré-concepção destas famílias, em sua maioria empobrecidas, vistas e julgadas como desestruturadas, desorganizadas e até mesmo violentas pelas faltas que enfrentam em diversos níveis, como de oportunidades sociais, culturais, de políticas públicas de suporte, a vivência da pobreza e tudo que tal condição acarreta.

Em sintonia com essa preocupação com a família de adolescentes em conflito com a lei, entre as diretrizes do SINASE é reforçada que a experiência socioeducativa deve ter participação ativa da família, afirmando-se que a participação familiar é considerada

\section{POLÊM!CA $\mid$ LABORE}

Polêmica - Revista Eletrônica da Uerj - Rua São Francisco Xavier, 524, $1^{\circ}$ andar bloco D, sl.1001 • Tels.: +55 21 2334-4088/4087 • http://www.e-publicacoes.uerj.br/index.php/polemica/index http://www.labore.uerj.br • laboreuerj@yahoo.com.br 
"fundamental para a consecução dos objetivos da medida" (BRASIL, 2012b, p. 55). Nesse documento também é feita uma recomendação assinalando que ações e atividades dentro do sistema socioeducativo ao serem planejadas devem considerar a realidade familiar e comunitária dos adolescentes, pensando em um trabalho coletivo voltado a busca de soluções para as dificuldades existentes (ZAMORA; PEREIRA, 2013, p. 153).

Estas legislações e normativas assinalam para um caminho de superação de preconceitos e exclusões, com o reconhecimento dos novos arranjos afetivos de forma legal, com os direitos e deveres que cabem àqueles responsáveis por seu núcleo e por seus componentes.

Um dado importante, levantado na pesquisa "Trajetórias", em relação à convivência familiar foi o percentual de $68,7 \%$ dos adolescentes que assinalaram a família como um grupo de afeto e apoio e 26,1\% apontaram a relação entre os familiares como uma relação a respeitar, independente de se ter afeto ou não entre seus membros.

A importância de abertura para a singularidade dos arranjos familiares que se fazem realidade é atual, com novas formas de conviver sendo criadas, com a construção de famílias de formas, tipos, cores e classes sociais variadas, onde os familiares que compõem este núcleo alcançaram o direito de ter sua dimensão particular, sexual e parental expressa de forma verdadeira e aberta. Estas famílias buscam a superação das violações de direitos que enfrentam, sem serem colocadas à deriva por discriminações múltiplas, fortalecendo-se na organização de coletivos de maneiras diversas, entre outras formas de ações de resistência e fortalecimento (CAMURI et al., 2012, p. 46).

Acerca da composição dos núcleos familiares, em vivências de situações de conflito, adoecimento ou perda, os adolescentes sinalizaram dados que merecem atenção: em pergunta sobre a relação conjugal dos pais, os adolescentes afirmaram que 58,6\% de seus pais ou responsáveis são divorciados, 45,6\% declararam que ao menos um dos responsáveis já apresentou problema com uso de álcool ou droga e 39,4\% dos adolescentes já enfrentaram uma perda por morte de um dos responsáveis.

Confirmando que a família é uma referência positiva, 91,5\% dos participantes apontaram os pais/responsáveis como aqueles que dão suporte quando eles têm necessidade de apoio emocional, recebendo deles também incentivo para os estudos (93,8\%) (JULIÃO; MENDES, 2019).

\section{POLÊM!CA $\mid$ LABORE}

Polêmica - Revista Eletrônica da Uerj - Rua São Francisco Xavier, 524, $1^{\circ}$ andar bloco D, sl.1001 • Tels.: +55 21 2334-4088/4087 • http://www.e-publicacoes.uerj.br/index.php/polemica/index http://www.labore.uerj.br • laboreuerj@yahoo.com.br 
O total de $85 \%$ declarou ter interações com pessoas em quem podem confiar, porém a experiência e o sentimento de abandono alcançou um percentual de 39,4\% (JULIÃO; MENDES, 2019, p. 50). Sentimentos esgarçados por experiências abruptas de perda ou rompimento por vezes traumáticas não impedem os mais jovens de ainda acreditar em relações de amizade e solidariedade, que podem fortalecer a cada um e ao coletivo e direcionar para rumos produtivos seus caminhos.

\section{Territórios}

Sobre territórios, enfatiza-se que um grande percentual de adolescentes e familiares reside nas favelas do estado do Rio de Janeiro. Um dado que assinala dificuldades cotidianas é o percentual de 71,6\% que declarou residir em territórios de conflito armado (entre policiais, milicianos, traficantes e suas facções) e três quartos do total dos adolescentes afirmaram viver em uma zona de guerra $(75 \%)$.

$\mathrm{Na}$ "Trajetórias" (JULIÃO; MENDES, 2019, p. 21-22), os dados do perfil do adolescente evidenciaram uma realidade já conhecida pelos socioeducadores: a grande maioria dos respondentes é de adolescentes advindos das camadas sociais mais pobres, tem entre $16 \mathrm{e}$ 18 anos de idade $(81,1 \%)$, mais de $70 \%$ são negros - 76,2\% afirmaram ser pardos ou pretos, e em grande número interromperam os estudos entre o primeiro e segundo segmento do ensino fundamental.

Outros estudos e levantamentos - como os apresentados pelo Ministério dos Direitos Humanos, que publicou o "Levantamento Anual do SINASE 2016" (BRASIL, 2018); do Instituto Brasileiro de Geografia e Estatística com informações geográficas e estatísticas populacionais, como a "Pesquisa Nacional por Amostra de Domicílios" (IBGE, 2016); o Instituto de Pesquisa Econômica Aplicada com a publicação da Nota Técnica (SILVA; OLIVEIRA, 2015); do Conselho Nacional de Justiça, com a edição do "Panorama Nacional: A execução das medidas socioeducativas de internação" (CNJ, 2012), entre outros - prosseguem encontrando esse perfil que remete a um grupo historicamente discriminado e vulnerável em diversos níveis: no enfrentar a falta de recursos para subsistência, na descontinuidade no processo escolar, o enfrentamento de situações violentas, que provoca a necessidade de buscar formas de sobreviver. Apesar disso, mais da metade dos adolescentes entrevistados $(51,1 \%)$

\section{POLÊM!CA $\mid$ LABORE}

Polêmica - Revista Eletrônica da Uerj - Rua São Francisco Xavier, 524, $1^{\circ}$ andar bloco D, sl.1001 • Tels.: +55 21 2334-4088/4087 • http://www.e-publicacoes.uerj.br/index.php/polemica/index http://www.labore.uerj.br • laboreuerj@yahoo.com.br 
afirmou residir há mais de oito anos na mesma região e que não gostariam de se mudar (JULIÃO; MENDES, 2019, p. 24-27).

Gonçalves (2013) aborda, em seu trabalho acerca da dualidade cidade versus favela, que existe um movimento social paradoxal, do afastar e aproximar a favela da cidade, do "construir" e destruir nos espaços. Assinala o autor que desde sempre houve uma ambivalência em relação às favelas, colocando a população favelada em situação de precariedade jurídica, com todas as incertezas da propriedade. População que, em grande maioria, é composta por pessoas negras, procurando viver mais próxima ao trabalho, com menos taxas estaduais e municipais para pagar, para baratear o custo da moradia. Esta precariedade urbanística e fundiária, promovida pelas brechas da gestão municipal e por interesses econômicos, acaba por servir para “justificar" a ausência de investimentos consistentes em políticas públicas locais e de provisão (ou inadequação) de serviços coletivos. Os próprios moradores, inseguros de seus direitos de se manter nas casas, sem sofrer a perda de tudo que possa ter sido construído, podem temer considerar as casas como suas e fazer planos e gastos baseados em um patrimônio incerto e um direito duvidoso (GONÇALVES, 2013, p. 2).

\section{Considerações finais}

Todas estas questões sensíveis pretendem se somar na reflexão acerca da vida destes adolescentes e apontam para o que realmente se faz necessário na construção socioeducativa. Melhor ainda: o que poderia ser feito para que a maioria dos adolescentes não estivesse em privação de liberdade, no envolvimento com perigos, problemas e delitos. São questões que demandam maior atenção de estudiosos, profissionais de campo, dos próprios familiares e com a participação dos adolescentes, para se pensar no que eles podem precisar enquanto pessoas em intenso processo de desenvolvimento e formação.

O território de pertencimento de adolescentes e familiares tem uma importância ímpar, pois, como pontua Barbosa (2010), os territórios de moradia, vizinhança e convivência estão mais complexos e difíceis na atualidade, porém continuam a ser referência integrativa dos sujeitos, pois todos "somos sujeitos da política e portadores de projetos da sociedade" (BARBOSA, 2010, s/p); de uma política do espaço, de uma cidade, como o próprio nome "política" sugere. A participação protagonista do adolescente nas questões de seu território, comunidade e cidade deveria ser estimulada.

\section{POLÊM!CA | LABORẸ}

Polêmica - Revista Eletrônica da Uerj - Rua São Francisco Xavier, 524, $1^{\circ}$ andar bloco D, sl.1001 • Tels.: +55 21 2334-4088 / 4087 • http://www.e-publicacoes.uerj.br/index.php/polemica/index http://www.labore.uerj.br • laboreuerj@yahoo.com.br 
A superação do equivocado movimento de tentar resolver o problema da criminalidade juvenil diminuindo a maioridade penal, a resposta adequada para toda e qualquer violação de direitos, violência e vulnerabilidade dessa população, o impedimento dos assassinatos de crianças e de adolescentes, a extinção dos estigmas e preconceitos - em especial o racismo -, são condições básicas para mudanças que precisam acontecer no cenário político que se volta à população socioeducativa tanto no sistema como em seus territórios, no cotidiano de cada um, de forma ampla.

É necessária a abertura de oportunidades nas áreas socioculturais e políticas, de outra concepção da disponibilidade de recursos e equipamentos sociais para resguardar estes jovens dentro da educação, da ocupação do espaço social sem a fragmentação de suas existências, enfim, para outras possibilidades que não o cometimento de atos infracionais, institucionalizações sucessivas e mais gravosas e numerosos riscos - e sim ações criativas e produtivas para seu desenvolvimento e participação social porque fundamentadas a partir do conhecimento concreto de suas vidas.

Considerando na atualidade o quanto as "políticas são cada vez mais tecnologias subjetivas, dada a nova relação entre o poder e a vida (biopoder), é necessário problematizar os modos de defesa dos Direitos Humanos". Assim Vicentin (2011), na direção de promover a existência singularizada de sujeitos sociais como os adolescentes em conflito com a lei, assinala que

Em outros termos: não se trata de fazer a apologia da infração ou da transgressão; mas, se o adolescente em conflito com a lei puder ser hoje menos "marginal", seria importante que isso não se fizesse à custa da patologização ou da pacificação das dissidências como se pode acompanhar na brevidade trágica ou dramática das rebeliões e nas fagulhas de indiscernibilidade entre desordem e política que eles protagonizam.

Desnaturalizar a violência juvenil supõe ressituar nas lutas pelo poder a violência exercida e padecida pelos jovens (VICENTIN, 2011, p. 109).

\section{Referências}

BARBOSA, J. L. Cidade e Território: desafios da reinvenção política do espaço público. Combate Racismo Ambiental. Rio de Janeiro, 12 de agosto de 2010. Disponível em: https://acervo.racismoambiental.net.br/2010/08/12/cidade-e-territorio-desafios-da-reinvencao-politica-doespaco-publico/. Acesso em: 30 mar. 2019.

\section{POLÊM!CA $\mid$ LABORE}

Polêmica - Revista Eletrônica da Uerj - Rua São Francisco Xavier, 524, $1^{\circ}$ andar bloco D, sl.1001 • Tels.: +55 21 2334-4088 / 4087 • http://www.e-publicacoes.uerj.br/index.php/polemica/index http://www.labore.uerj.br • laboreuerj@yahoo.com.br 
BRASIL. Constituição da República Federativa do Brasil. Diário Oficial [da] República Federativa do Brasil. Senado Federal, Brasília, DF, 1988. Disponível em:

<http://www.planalto.gov.br/ccivil_03/Constituicao/Constituicao.htm>. Acesso em: 30 mar. 2019.

Estatuto da Criança e do Adolescente. Lei 8.069/90 de 13 de julho de 1990. Dispõe sobre o Estatuto da Criança e do Adolescente e dá outras providências. Diário Oficial da União, Brasília, DF, 16 jul. 1990, 27 set. 1990. Disponível em: http://www.planalto.gov.br/ccivil_03/leis/18069.htm. Acesso em: 30 mar. 2019.

Lei $\mathrm{n}^{\circ}$ 12.594, de 18 de janeiro de 2012. Institui o Sistema Nacional de Atendimento Socioeducativo (Sinase). Diário Oficial da União, Brasília, DF, 19 jan. 2012a. Disponível em: http://www.planalto.gov.br/ ccivil_03/_ato2011-2014/2012/lei/112594.htm. Acesso em: 30 mar. 2019.

Sistema Nacional de Atendimento Socioeducativo - SINASE. Brasília: CONANDA; UNICEF, 2012b. Disponível em: ftp://balcao.saude.ms.gov.br/horde/sisppi/unei/Legislacao/Sinase.pdf. Acesso em: 30 mar. 2019.

. Levantamento anual SINASE 2016. Brasília: Ministério dos Direitos Humanos, 2018. Disponível em: <https://prioridadeabsoluta.org.br/wp-content/uploads/2019/05/levantamento_2016final_sinase.pdf〉. Acesso em: 24 out. 19

Ministério do Desenvolvimento Social e Combate à Fome, Secretaria Especial de Direitos Humanos. Plano nacional de promoção, proteção e defesa do direito de crianças e adolescentes à convivência familiar e comunitária. Brasília, DF: 2006.

CAMURI, A. C.; SERENO, G. C.; ZAMORA, M. H., QUINTANA, J. T. Direitos sexuais no sistema socioeducativo do Rio de Janeiro. Mnemosine, Rio de Janeiro, v. 8, n. 1, p. 43-71, 2012. Disponível em: https://www.e-publicacoes.uerj.br/index.php/mnemosine/article/view/41574. Acesso em: 30 mar. 2019.

CNJ - CONSELHO NACIONAL DE JUSTIÇA. Panorama Nacional. A execução das medidas socioeducativas de internação. Programa justiça ao jovem. Brasília: CNJ, 2012. Disponível em: https://www.cnj.jus.br/wp-content/uploads/2011/02/panorama_nacional_doj_web.pdf. Acesso em: 30 mar. 2019.

GONÇALVES, R. S. A política, o direito e as favelas do Rio de Janeiro: um breve olhar histórico. URBANA: Revista Eletrônica do Centro Interdisciplinar de Estudos sobre a Cidade, Campinas, v. 1, n. 1, p. 1-23, abr. 2013. DOI: https://doi.org/10.20396/urbana.v1i1.8635115.

IBGE - INSTITUTO BRASILEIRO DE GEOGRAFIA E ESTATÍSTICA. Pesquisa nacional por amostra de domicílios. Síntese de Indicadores 2015. Rio de Janeiro: IBGE, 2016. Disponível em: https://biblioteca.ibge.gov.br/visualizacao/livros/liv98887.pdf. Acesso em: 30 mar. 2019.

JULIÃO, E.; MENDES, C. (Coord.). Trajetórias de vida de jovens em situação de privação de liberdade no sistema socioeducativo do estado do Rio de Janeiro. Rio de Janeiro: Degase, 2019. Disponível em: http://www.degase.rj.gov.br/publicacoes2019/RelatorioPesquisaJovens.pdf. Acesso em: 30 mar. 2019.

LESSA, A.; LOPES, E. R.; SILVA, M. T. A. Visita íntima no DEGASE: o exercício de um direito. In: JULIÃO, E.; MENDES, C.; ABDALLA, J. (Org.). Diversidade, violência e direitos humanos. Rio de Janeiro: Degase, 2015. p. 154-163.

SILVA, E. R. A.; OLIVEIRA, R. M. (Org.). Nota Técnica, No 20. O Adolescente em Conflito com a Lei e o Debate sobre a Redução da Maioridade Penal: esclarecimentos necessários. Brasília: IPEA, 2015. Disponível em: http://www.ipea.gov.br/portal/images/stories/PDFs/nota_tecnica/150616_ntdisoc_n20. Acesso em: 30 mar. 2019.

SILVA, M. T. A. Família, Socioeducação e Projeto Golfinhos: uma construção coletiva. Paraná: Appris, 2018.

\section{POLÊM!CA $\mid$ LABORË}

Polêmica - Revista Eletrônica da Uerj - Rua São Francisco Xavier, 524, $1^{\circ}$ andar bloco D, sl.1001 • Tels.: +55 21 2334-4088 / 4087 • http://www.e-publicacoes.uerj.br/index.php/polemica/index http://www.labore.uerj.br • laboreuerj@yahoo.com.br 
SILVA, M. T. A.; ZAMORA, M. H. Visita íntima no sistema socioeducativo do Rio de Janeiro: uma construção interdisciplinar. Rev. Bras. Adolescência e Conflitualidade, v. 11, p. 1-13, 2014. Disponível em: https://seer.pgsskroton.com/index.php/adolescencia/article/view/2962/2788. Acesso em: 30 mar. 2019.

VICENTIN, M. C. G. Corpos em rebelião e o sofrimento-resistência: adolescentes em conflito com a lei. Tempo soc., São Paulo, v. 23, n. 1, p. 97-113, 2011. Disponível em:

http://www.scielo.br/scielo.php?script=sci_arttext\&pid=S0103-20702011000100005\&lng=en\&nrm=iso. Acesso em: 30 mar. 2019.

VILHENA, J.; SOUZA, A. C. B.; UZIEL, A. P.; ZAMORA, M. H.; NOVAES, J. V. Que família? Provocações a partir da homoparentalidade. Revista Mal-Estar e Subjetividade, Fortaleza, v. 11, n. 4, p. 1639-

1658, dez. 2011. Disponível em: http://pepsic.bvsalud.org/ scielo.php?script=sci_arttext\&pid=S1518-

61482011000400014 \&lng=pt\&nrm=iso. Acesso em: 30 mar. 2019.

ZAMORA, M. H.; PEREIRA, I. Adolescente em conflito com a lei e suas famílias. In: JULIÃO, E.; VERGÍLIO, S. (Org.). Juventudes, políticas públicas e medidas socioeducativas. Rio de Janeiro: Degase, 2013. p. 147160 .

ZAPPE, J. G.; DIAS, A. C. G. Violência e fragilidades nas relações familiares: refletindo sobre a situação de adolescentes em conflito com a lei. Estudos de Psicologia, Natal, v. 17, n. 3, p. 389-395, set./dez. 2012. DOI: http://dx.doi.org/10.1590/S1413-294X2012000300006.

Recebido em: 30/01/2019.

Aceito em: 30/03/2019.

\section{POLÊM!CA $\mid$ LABORE}

Polêmica - Revista Eletrônica da Uerj - Rua São Francisco Xavier, 524, $1^{\circ}$ andar bloco D, sl.1001 • Tels.: +55 21 2334-4088 / 4087 • http://www.e-publicacoes.uerj.br/index.php/polemica/index http://www.labore.uerj.br • laboreuerj@yahoo.com.br 